\title{
Mechanochemically synthesized kalsilite based bioactive glass-ceramic composite for dental vaneering
}

\author{
Pattem Hemanth Kumar ${ }^{1}$ Vinay Kumar Singh ${ }^{1} \cdot$ Pradeep Kumar $^{2}$
}

Received: 11 May 2015/Accepted: 10 August 2015/Published online: 19 August 2015

(c) The Author(s) 2015. This article is published with open access at Springerlink.com

\begin{abstract}
Kalsilite glass-ceramic composites have been prepared by a mechanochemical synthesis process for dental veneering application. The aim of the present study is to prepare bioactive kalsilite composite material for application in tissue attachment and sealing of the marginal gap between fixed prosthesis and tooth. Mechanochemical synthesis is used for the preparation of microfine kalsilite glass-ceramic. Low temperature frit and bioglass have been prepared using the traditional quench method. Thermal, microstructural and bioactive properties of the composite material have been examined. The feasibility of the kalsilite to be coated on the base commercial opaque as well as the bioactive behavior of the coated specimen has been confirmed. This study indicates that the prepared kalsilite-based composites show similar structural, morphological and bioactive behavior to that of commercial VITA VMK95 Dentin 1M2.
\end{abstract}

Keywords Mechanochemical synthesis - Composite . Glass-ceramics · Coating $\cdot$ Simulated body fluid $\cdot$ Dental ceramic

\section{Introduction}

Ceramic-metal restorations are a beauty of porcelain and strength of a metal substructure. Metal/ceramic alloys are being challenged by manufacturers of frequent low cost

Vinay Kumar Singh

phkumar.rs.cer13@itbhu.ac.in; vinaycer@gmail.com

1 Department of Ceramic Engineering, Indian Institute of Technology (BHU), Varanasi, India

2 Department of Chemical Engineering and Technology, Indian Institute of Technology (BHU), Varanasi, India and exhibit superior physical properties (Mclean and Sced 1973; Kumar et al. 2014a, b). However, during the last few years, the technological parameters of dental ceramic alloys have been changed. Dental ceramic materials are bio-inert and unable to interacting with the surrounding tissues. Bioactive dental materials have been developed over the last decades (Chatzistavrou et al. 2010). According to Hench, bioactive glass produces a specific biological response at the interface of the material which results in the formation of a bond between the tissues and the material (Chatzistavrou et al. 2012; Hench and Paschall 1973). Ceramic materials are regularly used in dental restoration, which have specific properties such as similarity with natural tooth structure, wear resistance, high mechanical strength and durability in the oral environment. The main problems that occur with the patients are the secondary caries and cement dissolution, resulting in the marginal gap between existing tooth and restoration (Al-Noaman et al. 2013; Kokoti et al. 2001). This causes a bacterial attack leading to pulp irritation or necrosis and finally remove the prostheses (Kontonasaki et al. 2007). Alteration in this marginal gap leads to increase in the cell attachment and proliferation without affecting the physical-chemical and mechanical properties (Pitaru et al. 1988). It may decrease or eliminate cement dissolution and prevent the bacterial adhesion on the cement surface (Meijering et al. 1998). Chatzistavrou et al. described a successful synthesis of bioactive dental glass-ceramic composite using the sol-gel route. They have also reported the feasibility of developed material to be coated on the surface of dental ceramic substrates (Chatzistavrou et al. 2010). Furthermore, no work has been reported on the synthesis of kalsilite glass-ceramic using mechanochemical route and its formulation with bioglass to form a bioactive composite. 
The present work has been carried out to introduce a successful synthesis of bioactive kalsilite glass-ceramic composite materials with required characteristics for dental applications, especially for porcelain fused to metal system (PFM) used for crown, bridges etc. In this work, bioactive glass and kalsilite-based porcelain were prepared using a traditional melt-quenching method and mechanochemical route, respectively (Kumar et al. 2014). This new composite material is expected to have good thermal, bioactive and mechanical properties.

\section{Materials and methods}

\section{Preparation of kalsilite, bioglass and low temperature frit (LTF)}

AR grade aluminum oxide, potassium carbonate, and silicon dioxide (Loba Chemie Pvt. Ltd., Mumbai, India) were weighed in a stoichiometric ratio of kalsilite. This mixture was ground for $6 \mathrm{~h}$ in a high-energy planetary ball mill and subsequently heat treated at $1000{ }^{\circ} \mathrm{C}$ as discussed in our previous work (Kumar et al. 2014). Commercial Bioglass ${ }^{\circledR}$ 45S5 was prepared on a lab scale using traditional meltquenching in a platinum crucible at $1400{ }^{\circ} \mathrm{C}$. The molten frit was quenched in deionized water, dried at $110{ }^{\circ} \mathrm{C}$ for $2 \mathrm{~h}$ and subsequently pulverized to pass a 350 BSS mesh. A similar process was adopted for the preparation of LTF (Kumar et al. 2014).

\section{Formulation of kalsilite composite}

Composites were prepared by mixing $40 \mathrm{wt} \%$ kalsilite, $45 \mathrm{wt} \%$ bioglass and $15 \mathrm{wt} \%$ LTF. Compositions of the composite 1 (CMP-1) and composite 2 (CMP-2) (given in Table 1) were chosen on the basis of optimizations include glossiness of the surface, thermal expansion and translucency. The batch was ground in a planetary ball mill for 5 min to get a homogenous mixture. The ground mixture was further palletized using a uniaxial hydraulic press by applying a load of $200 \mathrm{MPa}$. These pellets were heat treated at $960{ }^{\circ} \mathrm{C}$ with a heating rate of $80{ }^{\circ} \mathrm{C} / \mathrm{min}$ using a furnace VITA VACUMAT 40T according to standard dental veneering firing cycle pre-programmed by VITA under vacuum. The vacuum was started at $500{ }^{\circ} \mathrm{C}$ and released at $960{ }^{\circ} \mathrm{C}$.

Table 1 Batch composition of composites

\begin{tabular}{lllll}
\hline Composites & Kalsilite & Kalsilite $\mathrm{MgF}_{2}$ & Bioglass & LTF \\
\hline CMP-1 & 40 & - & 45 & 15 \\
CMP-2 & - & 40 & 45 & 15 \\
\hline
\end{tabular}

The bonding of CMP-1 and CMP-2 coating materials was analyzed on a substrate made of opaque (from VITA VMK 95 1M2 opaque Product no. B330212, VITA Zahnfabrik, Bad sackingen, Germany). The substrate powder was palletized in a similar manner by heating at $960{ }^{\circ} \mathrm{C}$. Veneer material was prepared by mixing of both the composites (CMP-1 and CMP-2) in a modeling liquid with powder to liquid ratio of 0.3 to make a thick slurry. It is spread manually using a spatula on the substrates. These specimens were fired up to $960{ }^{\circ} \mathrm{C}$ using VITA VACUMAT 40T.

\section{Characterizations}

\section{Phase identification and microstructural analysis}

X-ray diffraction of the composite (before and after heat treatment) was carried out using a portable XRD (Rigaku, Japan) employing $\mathrm{Cu} \mathrm{K} \alpha$ radiation with $\mathrm{Ni}$ filter operating at $30 \mathrm{~mA}$ and $40 \mathrm{kV}$. Diffraction peaks were analyzed using standard JCPDS file (PDF-2 database 2003). Micrographs of the fractured sample were recorded using scanning electron microscope (SEM) (INSPECT 50 FEI).

\section{Coefficient of thermal expansion (CTE)}

Coefficient of thermal expansion and the glass transition temperature $(\mathrm{Tg})$ of the composite material were examined using a dilatometer (supplied by VB Ceramic Consultants, India). For CTE measurements, material was compacted into a rectangular bar $(50 \times 10 \times 10 \mathrm{~mm})$ using a uniaxial hydraulic press by applying a load of $200 \mathrm{MPa}$ followed by heat treated up to $950{ }^{\circ} \mathrm{C}$ with heating rate $80^{\circ} \mathrm{C} / \mathrm{min}$ (according to manufacturer's instructions).

\section{Preparation of SBF}

Simulated body fluid solution was prepared by dissolving analytical reagent grade $\mathrm{NaCl}, \mathrm{KCl}, \mathrm{NaHCO}_{3}, \mathrm{MgCl}_{2} .6$ $\mathrm{H}_{2} \mathrm{O}, \mathrm{CaCl}_{2}$ and $\mathrm{KH}_{2} \mathrm{PO}_{4}$ in double distilled water and buffered at $\mathrm{pH} 7.25$ with tris (hydroxymethyl) aminomethane (TRIS) and $1 \mathrm{~N} \mathrm{HCl}$ at $35-37{ }^{\circ} \mathrm{C}$ (Kokubo and Takadama 2006).

\section{Bioactivity test}

The formulated composites have been veneered on the surface of the substrate to study its bioactivity and surface morphology. Furthermore, the formation of hydroxyapatite (HAp) on the interface was also studied. HAp forming ability of the coated specimens was observed through 
immersion in simulated body fluid (SBF). For these testing's, three specimens of dimensions $10 \mathrm{~mm}$ diameter and $2 \mathrm{~mm}$ thickness were prepared and immersed in SBF ( $40 \mathrm{ml}$ ) for 7 and 21 days. At the end of the selected time periods, samples were separated from the SBF solution, rinsed with distilled water and dried in an electrical oven for further analysis. SBF-treated samples were examined by SEM and FTIR to evaluate the possible formation of HAp layer on the material surface as a marker of the bioactive behavior.

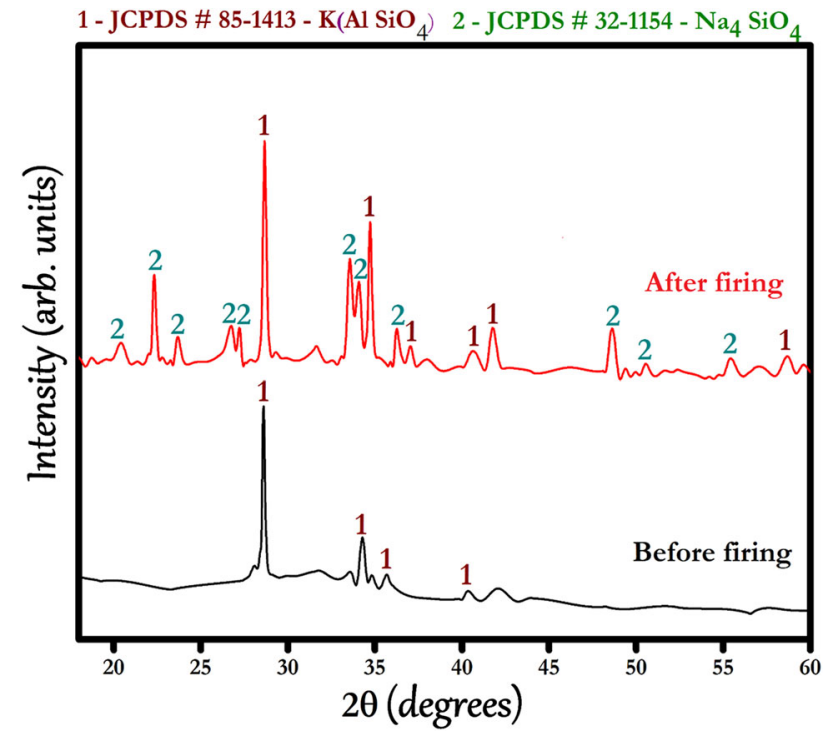

Fig. 1 XRD patterns of kalsilite composite before and after heat treatment

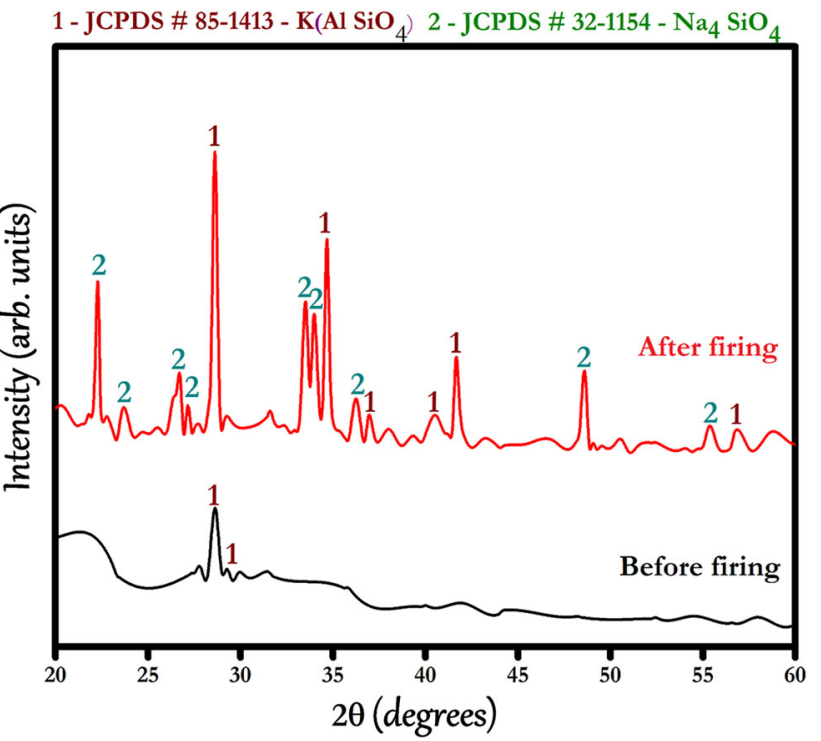

Fig. $2 \mathrm{XRD}$ patterns of kalsilite $\mathrm{MgF}_{2}$ composite before and after heat treatment

\section{Results and discussion}

\section{Phase analysis}

Figures 1 and 2 show the XRD patterns of all the kalsilite composites before and after firing. Diffraction peaks are well matched to JCPDS Card No. 32-1154. Before firing, kalsilite has been detected as a crystalline phase along with some amorphous phase in both composites. Furthermore $\mathrm{Na}_{2} \mathrm{O} . \mathrm{SiO}_{2}$ phase has been found as a crystalline phase after firing along with kalsilite as a major phase in both CMP-1 and CMP-2. This may form due to the presence of some free $\mathrm{Na}_{2} \mathrm{O}$ and $\mathrm{SiO}_{2}$ components in the matrix. Figures 1 and 2 show that the peak intensity corresponds to kalsilite phase is higher in CMP-2 as compared to CMP-1. It is therefore concluded that $\mathrm{MgF}_{2}$ helps in the formation of kalsilite as a major phase (Kumar et al. 2014).

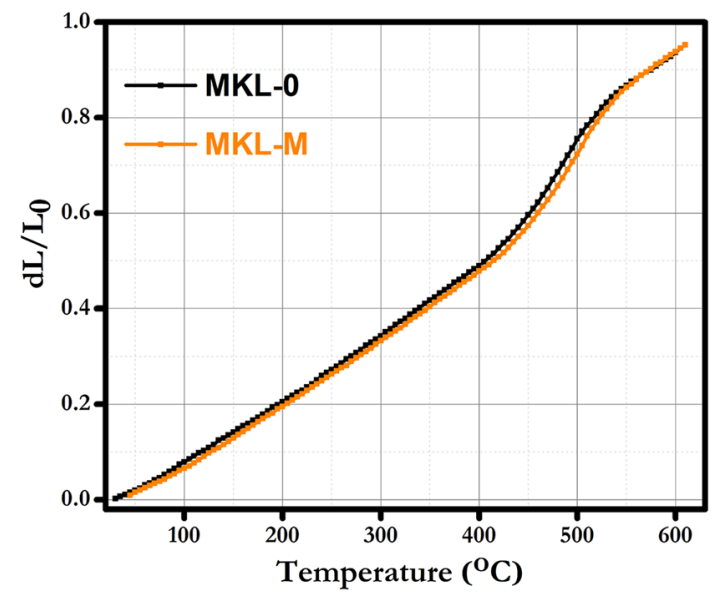

Fig. 3 CTE curves of kalsilite composites MCL-1

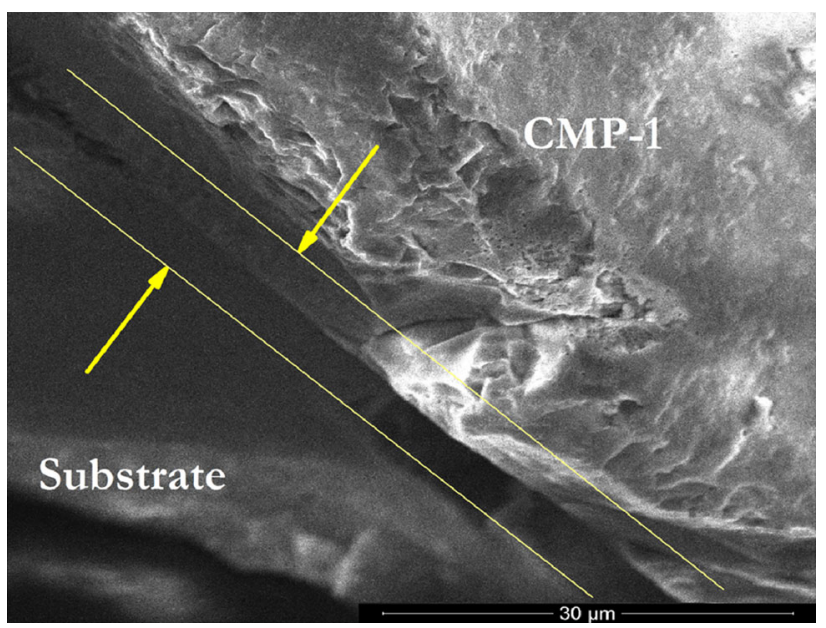

Fig. 4 SEM image of the fracture surface of CMP-1 interface of coated on subtract 


\section{Coefficient of thermal expansion (CTE)}

Thermal expansion is the important essential for veneering glass-ceramic fused to metal restorations. When a dental ceramic is used on a substrate, then CTE must be exact to confirm good attachment of the dental prosthesis. There is a possibility of formation of the cracks if a mismatch among the CTE of the ceramic coating and the substrate exists. Figure 3 shows the result of CTE curves of kalsilite composites. Values of CTE and glass transition $(\mathrm{Tg})$ of the composites have been found to be $15.9 \times 10^{-6} /{ }^{\circ} \mathrm{C}$ and $535{ }^{\circ} \mathrm{C}$ for CMP- $1,15.6 \times 10^{-6} /{ }^{\circ} \mathrm{C}$ and $545^{\circ} \mathrm{C}$ for CMP2 , respectively. It is nearer to the CTE $\left(14.5 \times 10^{-6} /{ }^{\circ} \mathrm{C}\right)$ obtained for dentine (VITA VMK95 Dentin 1M2). CMP-1 has slightly high CTE and low Tg than that of CMP-2. A high CTE of ceramic is to be assured a good bonding with the substrates. The existence of kalsilite phase in composite

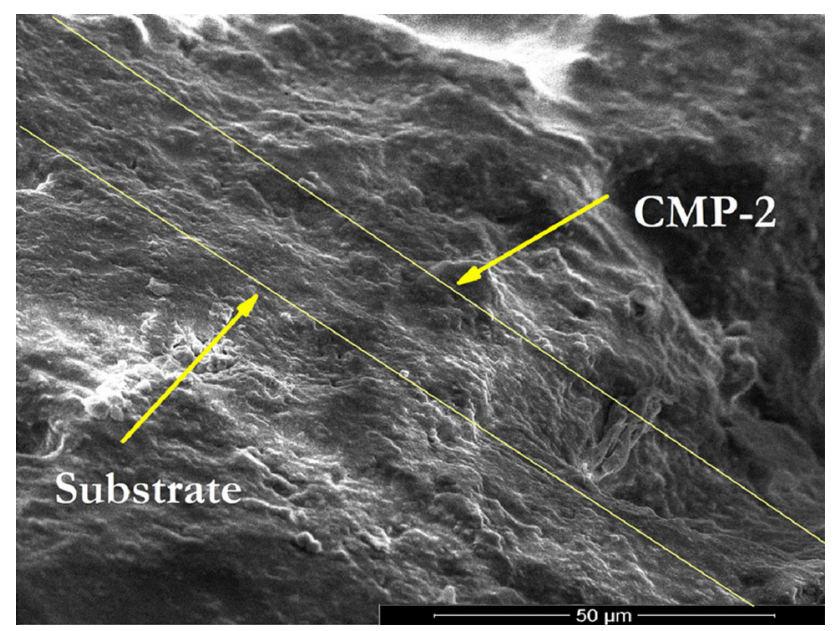

Fig. 5 SEM image of the fracture surface of CMP-2 interface of coated on subtract material causes an increase in the CTE value. Kalsilite has a high CTE which improves the whole CTE of the dental ceramic subsequently thermally compatible with the substrates (Kumar et al. 2014).

\section{Surface morphology}

Figures 4 and 5 show the surface morphology of interface layer between the composite and the substrate (composite coated on a commercial vita opaque substrate). This morphology is a confirmation of qualitatively good bonding between the composite and substrate. There are no cracks or peeling off or gap present in the interface region. This confirms that the CTE of composite and substrate is well coordinated (Kumar et al. 2015).

\section{Bioactivity in SBF}

Kalsilite composite samples immersed in SBF solution have been analyzed using SEM and FTIR. Immersed in SBF led to the formation of a HAp layer on the surface of the samples. Figures 6 and 7 show the development of HAp layer on the surface of the samples after immersing in SBF solution for 7 days. In FTIR (Figs. 8, 9) spectra, strong peaks appeared in the range of $1150-900$ and $650-500 \mathrm{~cm}^{-1}$ correspond to the stretching vibrations of $\mathrm{PO}_{4}^{-3}$. This is indication of the formation of hap layer on the surface of the sample after immersion in SBF for 7 days at $37{ }^{\circ} \mathrm{C}$. The low intense peaks have been observed in the range $1500-1400 \mathrm{~cm}^{-1}$ indicate the presence of $\mathrm{CO}_{3}^{-2}$ molecules in the sample. There is also a peak at $450 \mathrm{~cm}^{-1}$ allocated to the bending vibration mode of $\mathrm{Si}-\mathrm{O}$ bond. The results of FTIR are also in conformity with the results of SEM. The formation of HAp layer on the surface of the samples includes few steps reactions (Hench and Paschall 1973). First is exchange between the alkali ions in
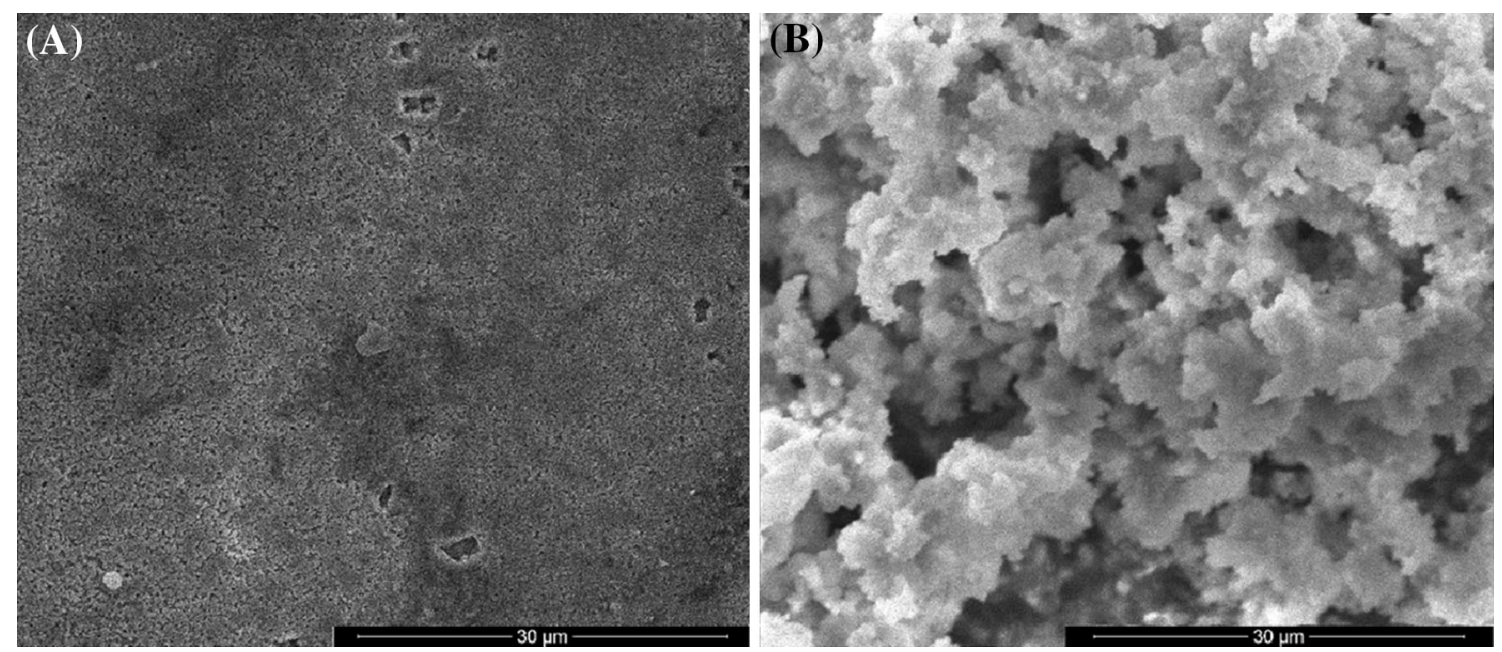

Fig. 6 SEM pictures of the CMP-1 a before and $\mathbf{b}$ after immersion for 7 days in SBF solution, presenting hydroxyapatite formation 

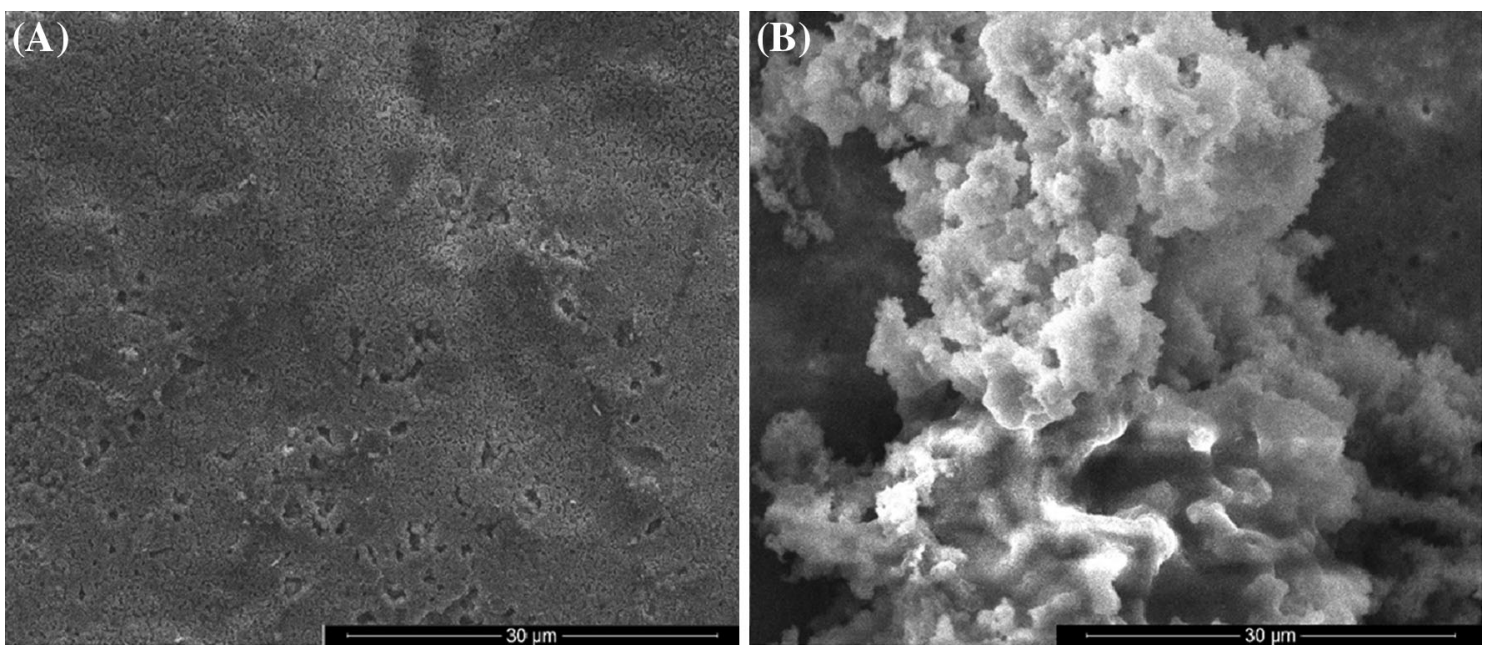

Fig. 7 SEM pictures of the CMP-2 a before and $\mathbf{b}$ after immersion for 7 days in SBF solution, presenting hydroxyapatite formation

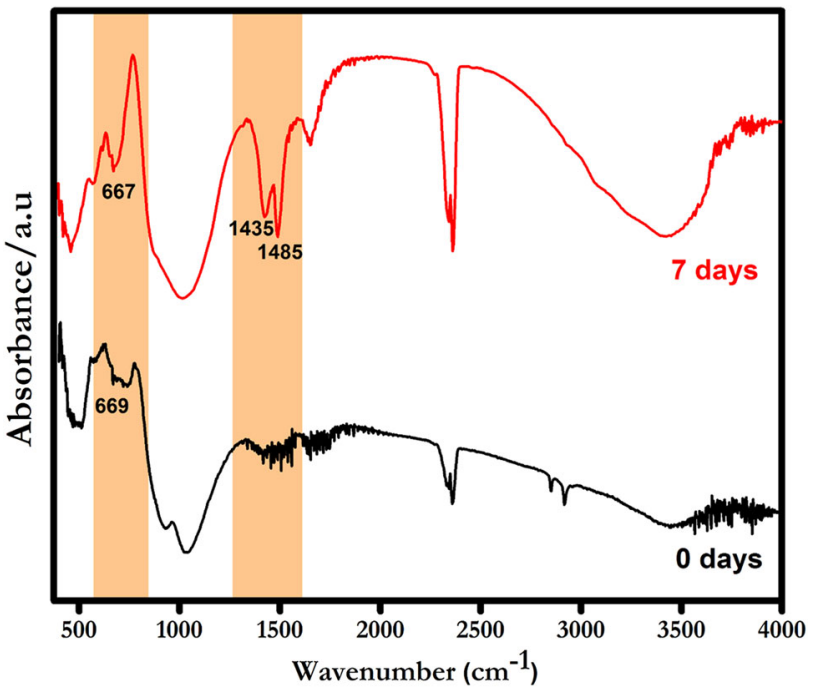

Fig. 8 FTIR absorbance bands of the CMP-1 before and after immersion in SBF solution for 0 and 7 days

the glass and the water. Second is breakdown of the silica network forming silanol bonds that re-polymerize to form a hydrated, high surface area, silica-rich layer. Silica-rich surface enhances the migration of $\mathrm{Ca}^{2+}$ and $\mathrm{PO}_{4}{ }^{3-}$ to the surface forming an amorphous $\mathrm{CaP}$ layer which further crystallized in HAp layer.

\section{Conclusion}

The current work shows the successful mechanochemical synthesis of kalsilite-based composites for potential applications in dental restorations. The strong bonding of CMP1 and CMP-2 to be applied as a coating on the substrate has been confirmed by SEM. Hydroxyapatite layer formation

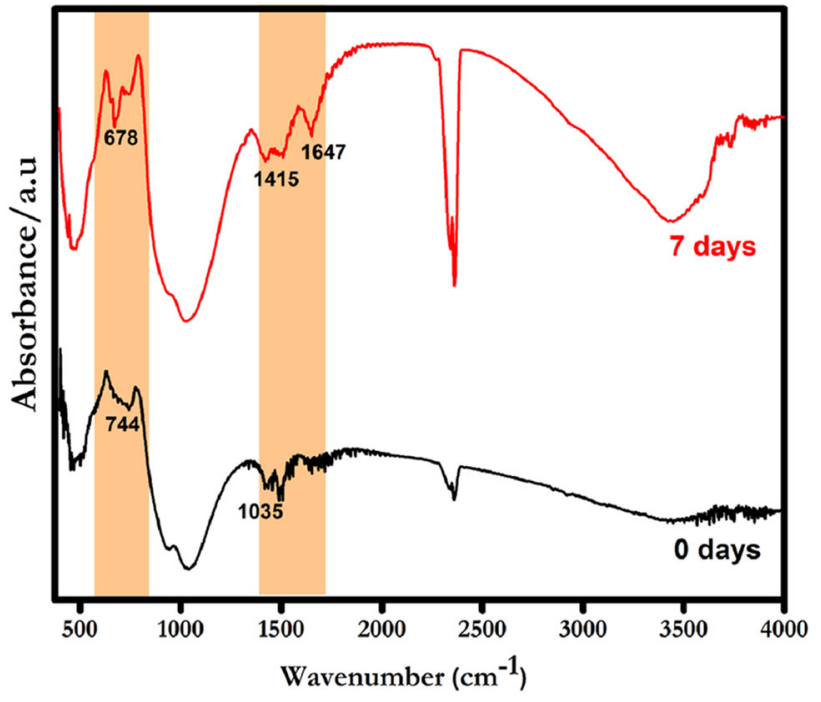

Fig. 9 FTIR absorbance bands of the CMP-2 before and after immersion in SBF solution for 0 and 7 days

on the surface of the CMP-1 and CMP-2 has been observed using FTIR and SEM. These composite materials may be used for dental veneering application. These materials will be further characterized by ion leachability test in different acidic agent and wettability test in the future.

Acknowledgments The authors gratefully acknowledge the financial support of DST [(TDT Division), Reference No. DST/SSTP/UP/ 197(G) 2012], Ministry of Science and Technology, New Delhi, India.

Open Access This article is distributed under the terms of the Creative Commons Attribution 4.0 International License (http:// creativecommons.org/licenses/by/4.0/), which permits unrestricted use, distribution, and reproduction in any medium, provided you give appropriate credit to the original author(s) and the source, provide a link to the Creative Commons license, and indicate if changes were made. 


\section{References}

Al-Noaman Ahmed, Rawlinson SCF, Hill Robert G (2013) Bioactive glass-stoichiometric wollastonite glass alloys to reduce TEC of bioactive glass coatings for dental implants. Mater Lett 94:69-71

Chatzistavrou X, Esteve D, Hatzistavrou E, Kontonasaki E, Paraskevopoulos K, Boccaccini AR (2010) Sol-gel based fabrication of novel glass-ceramics and composites for dental applications. Mater Sci Eng C 30:730-739

Chatzistavrou X, Tsigkou O, Amin HD, Paraskevopoulos K, Salih V, Boccaccini AR (2012) Sol-gel based fabrication and characterization of new bioactive glass-ceramic composites for dental applications. J Eur Ceram Soc 32:3051-3061

Hench LL, Paschall HA (1973) Direct chemical bond of bioactive glass ceramic materials to bone and muscle. J Biomed Mater Res Symp 4:25-42

Kokoti M, Sivropoulou A, Koidis P, Garefis P (2001) Comparison of cell proliferation on modified dental ceramics. J Oral Rehabil 28:799-804

Kokubo T, Takadama H (2006) How useful is SBF in predicting in vivo bone bioactivity. Biomaterials 27:2907-2915

Kontonasaki E, Sivropoulou A, Papadopoulou L, Garefis P, Paraskevopoulos K, Koidis P (2007) Attachment and proliferation of human periodontal ligament fibroblasts on bioactive glass modified ceramics. J Oral Rehabil 34:57-67

Kumar PH, Srivastava A, Kumar V, Jaiswal N, Kumar P, Singh VK (2014a) Role of $\mathrm{MgF}_{2}$ addition on high energy ball milled kalsilite: implementation as dental porcelain with low temperature frit. J Adv Ceram 3:332-338

Kumar PH, Srivastava A, Kumar V, Sharma S, Singh H, Kumar P, Singh VK (2014b) Role of $\mathrm{CaF}_{2}$ on mechanochemically synthesized leucite as dental veneering glass ceramics. Adv Appl Ceram 114:107-113

Kumar Pattem Hemanth, Singh Vinay Kumar, Srivastava Abhinav, Hira Sumit Kumar, Kumar Pradeep, Manna Partha Pratim (2015) Mechanochemically synthesized leucite based bioactive glass ceramic composite for dental veneering. Ceram Int 41:1161-11168

Mclean JW, Sced IR (1973) The gold alloy/porcelain bond. Trans Br Ceram Soc 5:229-238

Meijering AC, Creugers NH, Roeters FJ, Mulder J (1998) Survival of three types of veneer restorations in a clinical trial a 2.5 -year interim evaluation. J Dent 26:563-568

Pitaru S, Tal H, Soldinger M, Grosskopf A, Noff M, Periodont J (1988) Partial regeneration of periodontal tissues using collagen barriers. Initial obs Canine 59:380-386 